\title{
Evaluation of the awareness of, attitude to, and knowledge about fertility preservation in cancer patients among clinical practitioners in Hong Kong
}

\author{
Jacqueline PW Chung *, Terence TH Lao, TC Li
}

\section{A B S T R A C T}

Introduction: Individuals can be exposed to gonadotoxic agents in the course of treatment for cancers and other medical conditions. Fertility preservation refers to strategies that aim to preserve fertility by protecting it against the damage inflicted by gonadotoxic treatment. Many young patients are prescribed gonadotoxic treatment without prior counselling. This study aimed to study the awareness of, attitude to, and knowledge about fertility preservation among clinicians in Hong Kong.

Methods: This was a cross-sectional study carried out between June and December 2016 using a selfadministered questionnaire. The questionnaires were sent to clinicians in the departments of Clinical Oncology, Haematology, Obstetrics and Gynaecology, Paediatrics, and Surgery in various public hospitals of Hong Kong.

Results: In this survey, $36.5 \%$ (167 of 457) of clinicians responded. Of the respondents, only $45.6 \%$ were familiar with fertility preservation. The factors considered most important for referral were, in decreasing order of importance, prognosis of the patient, patient's desire to have children, time available before commencing gonadotoxic treatment, type of cancer, and type of gonadotoxic treatment. The majority of clinicians did not refer their patients for fertility preservation due to a lack of available time before treatment, considerable risk of recurrence, poor prognosis, financial constraints, need for cancer treatment as top priority at the time, and lack of awareness of such service. Almost all agreed that a dedicated centre should be set up for fertility preservation and $76.5 \%$ agreed that fertility preservation should be provided as a public service.

Conclusion: Awareness among clinical practitioners of fertility preservation remains weak. Education of clinicians and the establishment of a dedicated fertility preservation centre are required.

\section{Hong Kong Med J 2017;23:556-61 \\ DOI: 10.12809/hkmj176840}

JPW Chung *, MRCOG, FHKAM (Obstetrics and Gynaecology)
TTH Lao, MD, FRCOG

TC Li, PhD, FRCOG

Department of Obstetrics and Gynaecology, The Chinese University of Hong Kong, Shatin, Hong Kong

* Corresponding author: jacquelinechung@cuhk.edu.hk

New knowledge added by this study

- Awareness of and knowledge about fertility preservation among clinical practitioners remains weak.

- Factors considered most important for referral were, in decreasing order of importance, prognosis of the patient, the desire to have children, time available before commencing gonadotoxic treatment, type of cancer, and gonadotoxic treatment.

Implications for clinical practice or policy

- Increased awareness of fertility preservation among clinicians is required, especially of new strategies involved in reproductive technology.

- Education of clinicians and establishment of a dedicated fertility preservation centre, and an efficient referral system are required.

\section{Introduction}

The human gonads, both the ovaries and testes, are sensitive organs susceptible to injury by disease, medications, and chemotherapy and radiation for the treatment of cancers and other medical conditions including autoimmune diseases such as systemic lupus erythematosus and haematological diseases. ${ }^{1-3}$ Individuals who survive may later consider starting a family, yet by this time they often face problems of gonadal injury and ageing. If their fertility can be preserved before such treatment is performed, especially at a young age, individuals will be able to retain or regain their fertility after completion of treatment.

Current advances in reproductive technology have enabled fertility to be retained by preservation 
of gonadal function such that gametes as well as hormones continue to be produced despite damage inflicted by gonadotoxic treatment. Fertility preservation methods include fertility-sparing surgery, radiation shielding, and gonadotropinreleasing hormone agonists for gonadal suppression during chemotherapy. In addition, assisted reproductive technology_including intracytoplasmic sperm insemination; and oocyte, embryo and ovarian tissue cryopreservation-have expanded fertility preservation options that can now be applied to a broader spectrum of patients including those who are pre-pubertal, and those with insufficient time prior to initiation of gonadotoxic treatment. ${ }^{4-6}$

Although any adverse effects of treatment on fertility should have been discussed by clinicians before treatment, up to half of the patients are not referred to fertility specialists for fertility preservation. ${ }^{7}$ To the best of our knowledge, there is no local literature on the awareness of, attitude towards, and knowledge about fertility preservation among clinicians in Hong Kong. We therefore conducted a questionnaire survey to address this issue.

\section{Methods}

This was a cross-sectional survey to evaluate the awareness of, attitude towards, and knowledge about fertility preservation among local clinicians in Hong Kong. The study was conducted between June 2016 and December 2016. Ethical approval for the study was obtained from the institutional Survey and Behavioural Research Ethics Committee.

Eligible subjects were identified from the Specialist Register of Medical Council of Hong Kong who were clinicians worked in public hospitals and specialised in the field of Clinical Oncology, Haematology, Obstetrics and Gynaecology, Paediatrics, and Surgery. Potential candidates were selected by convenience sampling from each specialty from various hospitals and their work addresses identified via the electronic staff directory or organisational chart provided by the Hospital Authority intranet. The study questionnaire was mailed to them internally.

The self-administered questionnaire included a brief explanation of the survey. If the subject agreed to participate, they were asked to complete the questionnaire and return it in the stamped addressed envelope. The questionnaires were completed and returned anonymously.

The questionnaire comprised 29 items in two parts. The first part included questions about the baseline demographics and specialty of the participants. Their views on the demand for the fertility preservation service, factors they considered when making a decision about fertility preservation, and the difficulties encountered in discussing fertility

\section{評估香港醫生對癌症病人保留生育力的認知、 態度和知識}

\author{
鍾佩樺、勞子僖、李天照
}

引言 : 不幸罹癌的年輕患者, 他們接受癌症治療後, 生殖能力可能會 大大受損。保留生育力是指透過一些醫療程序, 為因接受抗癌療程或 疾病而引致生殖能力受損的患者, 保留內分泌功能及保存其生殖能 力。許多年輕癌症病人在沒有事先諮詢的情況下進行性腺毒性治療。 本研究旨在研究香港醫生對保留生育力的認知、態度和知識。

方法：這橫斷面調查採用自填問卷形式進行。於2016年6月至12月期 間發送問卷給香港各公立醫院的臨床腫瘤學、血液學、婦產科、兒科 和外科部門的臨床醫生

結果：本問卷研究的回應率為 $36.5 \%$ (即成功發出問卷 457 份, 收回 167 份）。受訪者中只有 $45.6 \%$ 熟悉關於保留生育力的問題。受訪者認 為轉介最重要的考慮因素為（按重要性順序排列）：患者預後、患者 希望有孩子的意欲、性腺毒素治療開始前時間的長短、癌症類型和性 腺毒素治療種類。醫生沒有向患者提及保留生育力, 主要是因為開始 治療前時間緊拙、復發風險高、預後不良、病人缺乏資金、當時以癌 症治療為首要考慮, 以及未認識保留生育力的服務。幾乎所有受訪者 都同意設立一個專門保存生殖力的中心, $76.5 \%$ 受訪者則認為此等應 屬於公共服務的範圍。

結論：醫生對癌症病人保留生育力的意識依然薄弱。臨床醫生須加強 有關知識, 並須設立一個專門保存生殖力的中心。

issues with their patients were examined. Practical questions about the potential costs and the need for a dedicated fertility preservation clinic were also addressed.

The SPSS (Windows version 20.0; IBM Corp, Armonk [NY], US) was used for data entry and analysis. Demographic data were summarised by means, medians, and percentages. The Chi squared test ( $\chi^{2}$ test) was used for categorical data such as comparing the awareness of fertility preservation among different specialties, cancer type, and demographic background. Student's $t$ test $(t$ test) was used for continuous variables of age and years of practice. Results with a $\mathrm{P}$ value of $<0.05$ were considered statistically significant.

\section{Results}

Of the 467 questionnaires sent to a convenient sample of clinicians, 10 were returned unopened because of an outdated work address. A total of 167 questionnaires of the remaining 457 questionnaires were returned, giving an overall response rate of $36.5 \%$. The response rates for specific specialties were: $55.3 \%(68 / 123)$ for obstetricians and gynaecologists, $37.5 \% \quad(48 / 128)$ for surgeons (general/breast/urology), $18.5 \% \quad(22 / 119)$ for paediatricians, and $16.5 \%$ (16/97) for haematologists or clinical oncologists. Table 1 summarises the baseline demographics of the respondents. Some of 
TABLE I. Demographics of respondents $(n=167)$

\begin{tabular}{|lc|}
\hline Demographics & $\begin{array}{c}\text { No. (\%) of } \\
\text { respondents }\end{array}$ \\
\hline Gender & \\
\hline Female & $90(53.9)$ \\
\hline Male & $65(38.9)$ \\
\hline Not specified & $12(7.2)$ \\
\hline Marital status & \\
\hline Single & $61(36.5)$ \\
\hline Married/cohabitating & $103(61.7)$ \\
\hline Not specified & $3(1.8)$ \\
\hline Religion & \\
\hline No & $77(46.1)$ \\
\hline Protestants & $59(35.3)$ \\
\hline Catholic & $22(13.2)$ \\
\hline Buddhism & $6(3.6)$ \\
\hline Hinduism & $1(0.6)$ \\
\hline Others & $2(1.2)$ \\
\hline Specialty & \\
\hline Obstetrics and gynaecology & $68(40.7)$ \\
\hline General surgery / breast surgery / urology & $48(28.7)$ \\
\hline Paediatrics & $22(13.2)$ \\
\hline Clinical / haematological oncology & $16(9.6)$ \\
\hline Medicine & $3(1.8)$ \\
\hline Others & $5(3.0)$ \\
\hline Not specified & $5(3.0)$ \\
\hline Practice settings & \\
\hline University-affiliated teaching hospital & $116(69.5)$ \\
\hline Non university-affiliated hospital & $51(30.5)$ \\
\hline Years of experience & \\
\hline Not specified & $(24.0)$ \\
\hline
\end{tabular}

the respondents did not answer all questions, hence the denominators of each response are stated.

Up to $85.0 \%(142 / 167)$ of respondents cared for cancer patients in their daily practice and $76.0 \%$ $(127 / 167)$ dealt with treatments that may threaten fertility. The most commonly encountered cancers were gynaecological cancer $(50.0 \%, 71 / 142)$, followed by urological cancer $(25.4 \%, 36 / 142)$, haematological cancer $(20.4 \%, 29 / 142)$, neurological cancer $(19.7 \%$, 28/142), musculoskeletal cancer (18.3\%, 26/142), gastrointestinal cancer $(16.2 \%, 23 / 142)$, and others $(6.3 \%, 9 / 142)$.

Only $45.6 \%(73 / 160)$ of the respondents were familiar with fertility preservation. The three most familiar means were sperm freezing $(66.3 \%, 108 / 163)$, followed by oocyte freezing $(65.0 \%, 106 / 163)$ and embryo freezing $(50.3 \%, 82 / 163)$. Table 2 shows the awareness of various fertility preservation strategies among clinicians from different specialties.

Nevertheless, $68.3 \%(112 / 164)$ of respondents had never referred a patient for fertility preservation. Among the 52 respondents who had, 88.5\% (46/52) had referred fewer than five patients and $11.5 \%$ had referred more than five patients over the past 12 months. Sperm cryopreservation was the most commonly referred fertility preservation method. There was no significant association of the demographic background of respondents in terms of age $(\mathrm{P}=0.334)$, gender $(\mathrm{P}=0.325)$, marital status $(\mathrm{P}=0.060)$, presence of any children $(\mathrm{P}=0.574)$, or practice setting $(\mathrm{P}=0.749)$ with awareness or frequency of referral for fertility preservation. Up to $90.7 \%(146 / 161)$ would consider referral of a patient to a fertility specialist for fertility preservation if it delayed treatment by 1 week, $83.2 \%(134 / 161)$ if the delay was $<2$ weeks, $41.6 \%$ (67/161) for $<4$ weeks, and $6.2 \%(10 / 161)$ for $<8$ weeks.

Table 3 shows the responses to questions about fertility preservation. Up to $76.5 \%(117 / 153)$ of the respondents agree that fertility preservation should be available as a public service. The top five difficulties encountered by clinicians in discussing fertility preservation were: no time before commencement of gonadotoxic treatment $(60.6 \%, 97 / 160)$, high risk of cancer recurrence $(53.8 \%, 86 / 160)$ or poor prognosis, financial constraints (46.9\%, 75/160), treating the cancer as top priority $(38.8 \%, 62 / 160)$, and not being aware of any place or person to whom their patients could be referred to $(35.0 \%, 56 / 160)$.

\section{Discussion}

Gonadotoxic treatments for cancer, especially those requiring chemotherapy with alkylating agents and total body irradiation or pelvic/whole-body radiation, have a significant negative impact on ovarian and testicular function. ${ }^{1}$ These impacts may be irreversible depending on the patient's age, total dose administered, and gonadal reserve at the time of treatment.

Fertility preservation has gained increasing attention worldwide over the past decade as treatment advances result in more and more survivors of childhood cancers and adult malignancies who are expected to lead a normal life and to start a family of their own. ${ }^{1}$

Our study revealed several important findings. First, it showed a rather low awareness of fertility preservation among our respondents. Most agreed that their patients should be referred for fertility preservation even if it meant a delay in their treatment. Although up to three quarters of respondents dealt with treatment that might impair 
TABLE 2. Awareness and familiarity of fertility preservation among different specialties

\begin{tabular}{|c|c|c|c|c|c|c|}
\hline & \multicolumn{6}{|c|}{ No. $(\%)$ of respondents } \\
\hline & $\begin{array}{l}\text { Obstetrics and } \\
\text { gynaecology }\end{array}$ & Surgery & Paediatrics & Oncology & Medicine & Others \\
\hline \multicolumn{7}{|c|}{ Are you aware of fertility preservation? $(n=160)$} \\
\hline Yes & $34(46.6)$ & $17(23.3)$ & $11(15.1)$ & $7(9.6)$ & $2(2.7)$ & $2(2.7)$ \\
\hline No & $33(37.9)$ & $32(36.8)$ & $11(12.6)$ & $7(8.0)$ & $2(2.3)$ & $2(2.3)$ \\
\hline \multicolumn{7}{|c|}{ Familiarity with the following fertility preservation procedures (can choose more than one) [n=163] } \\
\hline Fertility-sparing surgeries & $42(53.2)$ & $17(21.5)$ & $9(11.4)$ & $11(13.9)$ & $0(0)$ & $0(0)$ \\
\hline Radiation shielding & $26(33.3)$ & $24(30.8)$ & $15(19.2)$ & $10(12.8)$ & $1(1.3)$ & $2(2.6)$ \\
\hline GnRH agonists & $8(22.2)$ & $13(36.1)$ & $6(16.7)$ & $8(22.2)$ & $1(2.8)$ & $0(0)$ \\
\hline Sperm freezing & $33(30.6)$ & $33(30.6)$ & $18(16.7)$ & $16(14.8)$ & $5(4.6)$ & $3(2.8)$ \\
\hline Oocyte freezing & $46(43.4)$ & $29(27.4)$ & $16(15.1)$ & $10(9.4)$ & $3(2.8)$ & $2(1.9)$ \\
\hline Embryo freezing & $43(52.4)$ & $21(25.6)$ & $6(7.3)$ & $7(8.5)$ & $3(3.7)$ & $2(2.4)$ \\
\hline Ovarian or testicular tissue freezing & $31(62.0)$ & $8(16.0)$ & $7(14.0)$ & $3(6.0)$ & $1(2.0)$ & $0(0)$ \\
\hline All of the above & $21(63.6)$ & $5(15.2)$ & $4(12.1)$ & $1(3.0)$ & $1(3.0)$ & $1(3.0)$ \\
\hline \multicolumn{7}{|c|}{ Referred patient(s) for the following fertility preservation procedures over the past 12 months (can choose more than one) [ $\mathrm{n}=52$ ] } \\
\hline Fertility-sparing surgeries & $42(48.3)$ & $17(19.5)$ & $15(17.2)$ & $10(11.5)$ & $1(1.1)$ & $2(2.3)$ \\
\hline Radiation shielding & $26(33.3)$ & $24(30.8)$ & $15(19.2)$ & $10(12.8)$ & $1(1.3)$ & $2(2.6)$ \\
\hline GnRH agonists & $8(22.2)$ & $13(36.1)$ & $6(16.7)$ & $8(22.2)$ & $1(2.8)$ & $0(0)$ \\
\hline Sperm freezing & $33(32.0)$ & $33(32.0)$ & $18(17.5)$ & $16(15.5)$ & $3(2.9)$ & $0(0)$ \\
\hline Oocyte freezing & $46(42.6)$ & $29(26.9)$ & $16(14.8)$ & $10(9.3)$ & $3(2.8)$ & $4(3.7)$ \\
\hline Embryo freezing & $43(52.4)$ & $21(25.6)$ & $6(7.3)$ & $7(8.5)$ & $3(3.7)$ & $2(2.4)$ \\
\hline Ovarian or testicular tissue freezing & $31(62.0)$ & $8(16.0)$ & $7(14.0)$ & $3(6.0)$ & $1(2.0)$ & $0(0)$ \\
\hline All of the above & $21(63.6)$ & $5(15.2)$ & $4(12.1)$ & $1(3.0)$ & $1(3.0)$ & $1(3.0)$ \\
\hline
\end{tabular}

Abbreviation: $\mathrm{GnRH}=$ gonadotropin-releasing hormone

fertility, less than half were familiar with fertility preservation. Our previous study showed significant underutilisation of a sperm cryopreservation service over the past two decades. ${ }^{8}$ There is an imperative need to provide better education and campaigns to raise awareness about various options for fertility preservation available in Hong Kong.

Second, our study evaluated the difficulties or barriers encountered by clinicians in referring patients for fertility preservation. Similar to previous studies, a high risk of disease recurrence and poor prognosis discouraged discussion about future fertility. ${ }^{9-11}$ More than half of the respondents also expressed insufficient time for fertility preservation procedures before initiation of gonadotoxic treatment. Nonetheless sperm cryopreservation is a simple and effective method of preserving fertility for male patients who need to produce only a semen sample by masturbation for cryopreservation at any time before initiation of gonadotoxic treatment. ${ }^{8}$ In female patients, fertility preservation is slightly more complicated and time-consuming. Ovarian stimulation for oocyte or embryo cryopreservation takes at least 8 to 12 days although the introduction of random-start protocols for ovarian stimulation and ovarian tissue cryopreservation now provide a new option for those with insufficient time and for pre-pubertal adolescents..$^{5,6,12,13}$ Early referral to a fertility specialist at the time of diagnosis of disease and prior to treatment commencement is the key to maximising the success of fertility preservation and allows a greater window of opportunity for preserving fertility. ${ }^{14}$ Again, this highlighted the need for training and education of clinical practitioners in the most updated advances in assisted reproductive technology, especially in specialties other than obstetrics and gynaecology.

Third, almost all respondents agreed there was a need for a dedicated clinic or referral centre. Most suggested two centres, catering to both private and public patients. No such referral centre is currently available in Hong Kong. An important prerequisite is a quick and efficient system whereby patients can be referred for fertility preservation counselling by a fertility specialist as soon as their diagnosis of cancer is made. ${ }^{15}$ Moreover, proper regulations and 
TABLE 3. Answers to questions on awareness of and factors to consider for fertility preservation

\begin{tabular}{|c|c|}
\hline Question & No. $(\%)$ of respondents \\
\hline \multicolumn{2}{|c|}{$\begin{array}{l}\text { Are you aware of a special clinic or specialists who would be able to accept your referrals for fertility preservation? } \\
(n=163)\end{array}$} \\
\hline Yes & $90(55.2)$ \\
\hline No & $73(44.8)$ \\
\hline \multicolumn{2}{|c|}{$\begin{array}{l}\text { If there are no problems with resources, funding and technical expertise, which of the following is the single MOST } \\
\text { important factor you think you will consider when deciding for fertility preservation? }(n=160)\end{array}$} \\
\hline Prognosis of patient & $66(41.3)$ \\
\hline Patient's desire to have children & $51(31.9)$ \\
\hline Time available before gonadotoxic treatment & $23(14.4)$ \\
\hline Type of cancer & $8(5.0)$ \\
\hline Type of gonadotoxic treatment & $4(2.5)$ \\
\hline Logistic issues for service centre & $2(1.3)$ \\
\hline Sex of patient & $2(1.3)$ \\
\hline Religion of patient & $2(1.3)$ \\
\hline Marital status of patient & $1(0.6)$ \\
\hline Cost & $1(0.6)$ \\
\hline \multicolumn{2}{|c|}{ Do you think setting up a dedicated clinic/centre for fertility preservation counselling is necessary? $(n=164)$} \\
\hline No & $5(3.0)$ \\
\hline One centre accepting both private and public patients is sufficient & $55(33.5)$ \\
\hline At least two centres, one for private and one for public patients & $41(25.0)$ \\
\hline At least two centres catering for both private and public patients & $63(38.4)$ \\
\hline \multicolumn{2}{|c|}{ Do you think fertility preservation should be available as a public service? $(n=153)$} \\
\hline Yes & $117(76.5)$ \\
\hline No & $36(23.5)$ \\
\hline \multicolumn{2}{|c|}{$\begin{array}{l}\text { Do you think that standard educational materials provided by the professional bodies are important to you for } \\
\text { counselling patients to enhance their understanding on fertility preservation? }(n=159)\end{array}$} \\
\hline Yes & $147(92.5)$ \\
\hline No & $12(7.5)$ \\
\hline \multicolumn{2}{|l|}{ Have you heard of regulations relating to fertility preservation? $(n=160)$} \\
\hline Yes & $65(40.6)$ \\
\hline No & $95(59.4)$ \\
\hline \multicolumn{2}{|c|}{ Do you think practice guidelines are required for fertility preservation? $(n=160)$} \\
\hline Yes & $148(92.5)$ \\
\hline No & $12(7.5)$ \\
\hline \multicolumn{2}{|l|}{ Do you want to know more about fertility preservation? $(n=150)$} \\
\hline Yes & $113(75.3)$ \\
\hline No & $37(24.7)$ \\
\hline
\end{tabular}

guidelines about fertility preservation should be established and communicated to the public and clinicians. Printed information about the effect of cancer treatment on fertility and the options for fertility preservation techniques, including both established and experimental, should be available for all clinicians to hand out to their patients. A 24-hour hotline should be set up and contact addresses disseminated widely on websites or to clinicians who care for patients with cancer.

Fourth, financial constraints should be addressed. Cryopreservation of gametes and embryos is expensive and is currently only available in Hong Kong as a private service. Government and non-governmental organisations should consider funding this in selected patients. Up to $76.5 \%$ of our respondents agreed that fertility preservation should be provided as a public service. 
In addition, there appeared to be varying levels of awareness among clinicians from different specialties about fertility preservation techniques. Different specialists may be more or less exposed to the most up-to-date trends in the field of assisted reproductive technology. Our data were not sufficiently representative to explore this issue. Further studies are required to evaluate this.

Our study is limited by its small sample size and low response rate. Ideally, all clinicians from both public and private sectors of all specialties should be included but this would be costly and impractical. Our study included a higher proportion of clinicians from university-affiliated hospitals and this might have added additional self-selection bias to the study as they were more willing to participate in research. In addition, clinicians with an interest in this area may have been more likely to respond to this study. Potential candidates were sampled by convenience from each specialty from various hospitals and might not have represented the views of all clinicians. Caution should be exercised when making generalisations about these data from a sample group that was self-selected. Nonetheless this is the first study to evaluate the awareness of, attitude towards, and knowledge about fertility preservation among clinicians in Hong Kong. It provides important information that can be applied in setting up a fertility preservation centre and in the design of training modules and educational materials for clinical practitioners.

Reassuringly, our studies show an overall encouraging positive attitude among local clinicians towards fertility preservation, with the majority wanting to know more. Knowledge about fertility preservation techniques is insufficient. There is a need to improve awareness of and referral for this service. As the field of fertility preservation continues to grow, it is important to include the topic of fertility preservation in the curriculum of our medical schools to increase the knowledge and awareness of our future clinicians. Seminars, workshops, and conferences for those interested in this field should be regularly arranged. Fundraising campaigns and grants for research in this field should be encouraged. A multidisciplinary team and dedicated centre with an efficient referral system should be set up as soon as possible to provide fertility risk assessment and counselling for patients. Further studies are required to explore how fertility concerns are being addressed during the management of serious medical conditions, especially cancer care, and how clinicians can communicate with cancer patients about the options for fertility preservation.

\section{Acknowledgements}

We would like to thank Miss Elaine Yee-lee Ng,
Miss Sze-yan Lo, and Mr Ka-chun Keung for data collection and entry. We would also like to thank all the clinicians who participated in this study.

\section{Declaration}

All authors have disclosed no conflicts of interest.

\section{References}

1. Rodriguez-Wallberg KA, Oktay K. Fertility preservation during cancer treatment: clinical guidelines. Cancer Manag Res 2014;6:105-17.

2. Falcone T, Bedaiwy MA. Fertility preservation and pregnancy outcome after malignancy. Curr Opin Obstet Gynecol 2005;17:21-6.

3. Loren AW, Mangu PB, Beck LN, et al. Fertility preservation for patients with cancer: American Society of Clinical Oncology clinical practice guideline update. J Clin Oncol 2013;31:2500-10.

4. Ethics Committee of American Society for Reproductive Medicine. Fertility preservation and reproduction in patients facing gonadotoxic therapies: a committee opinion. Fertil Steril 2013;100:1224-31.

5. Dolmans MM, Jadoul P, Gilliaux S, et al. A review of 15 years of ovarian tissue bank activities. J Assist Reprod Genet 2013;30:305-14.

6. Donnez J, Martinez-Madrid B, Jadoul P, Van Langendonckt A, Demylle D, Dolmans MM. Ovarian tissue cryopreservation and transplantation: a review. Hum Reprod Update 2006;12:519-35.

7. Forman EJ, Anders CK, Behera MA. A nationwide survey of oncologists regarding treatment-related infertility and fertility preservation in female cancer patients. Fertil Steril 2010;94:1652-6.

8. Chung JP, Haines CJ, Kong GW. Sperm cryopreservation for Chinese male cancer patients: a 17-year retrospective analysis in an assisted reproductive unit in Hong Kong. Hong Kong Med J 2013;19:525-30.

9. Shimizu C, Bando H, Kato T, Mizota Y, Yamamoto S, Fujiwara Y. Physicians' knowledge, attitude, and behavior regarding fertility issues for young breast cancer patients: a national survey for breast care specialists. Breast Cancer 2013;20:230-40.

10. Arafa MA, Rabah DM. Attitudes and practices of oncologists toward fertility preservation. J Pediatr Hematol Oncol 2011;33:203-7.

11. Collins IM, Fay L, Kennedy MJ. Strategies for fertility preservation after chemotherapy: awareness among Irish cancer specialists. Ir Med J 2011;104:6-9.

12. Cakmak H, Rosen MP. Random-start ovarian stimulation in patients with cancer. Curr Opin Obstet Gynecol 2015;27:215-21.

13. Rashidi BH, Tehrani ES, Ghaffari F. Ovarian stimulation for emergency fertility preservation in cancer patients: a case series study. Gynecol Oncol Rep 2014;10:19-21.

14. Yee S, Fuller-Thomson E, Lau A, Greenblatt EM. Fertility preservation practices among Ontario oncologists. J Cancer Educ 2012;27:362-8.

15. Ghazeeri G, Zebian D, Nassar AH, et al. Knowledge, attitudes and awareness regarding fertility preservation among oncologists and clinical practitioners in Lebanon. Hum Fertil (Camb) 2016;19:127-33. 